ISSN: 0213-2087 e-ISSN: 2444-7080

DOI: https://doi.org/10.14201/shhcont3820204575

\title{
CIENCIA, PATRIA Y HONOR: LOS MÉDICOS E INGENIEROS Y LA MASCULINIDAD ROMÁNTICA EN ESPAÑA $(1820-1860)^{1}$
}

\author{
Science, Country and Honour: Physicians \\ and Engineers, and the Romantic Masculinity \\ in Spain (1820-1860)
}

\author{
Darina MARTYKÁNOVÁ \\ Universidad Autónoma de Madrid
}

Víctor M. NÚÑEZ-GARCÍA

Universidad de Sevilla

Recibido: 07/02/2020 Revisado: 20/06/2020 Aceptado: 10/07/2020

RESUMEN: A mediados del siglo XIX, los médicos e ingenieros españoles se apoyaron en la dimensión pública de su actividad profesional para encarnar la nueva masculinidad liberal. Las vías principales para hacerse reconocer como parte de las élites liberales eran dos. Primero, la vinculación con las instituciones del Estado en plena construcción. Segundo, el argumento de que su conocimiento y saber-hacer expertos contribuían al progreso de la civilización y al bien común. Explorando el vínculo entre la utilidad y las ciencias, que había quedado establecido ya en el discurso de la Ilustración, estos hombres argumentaron que su profesión les hacía particularmente útiles para la patria, tanto a la hora de fomentar las riquezas del país y la felicidad de sus habitantes, como a la hora de contribuir a afianzar la posición de España entre las «naciones de la Europa culta». ¿Qué papel desempeñó el género en este proceso? ¿Hubo rasgos específicos de las profesiones científicas que las significaron como masculinas? ¿Cómo interactuó el factor de clase con

1. Agradecemos a Nerea Aresti, María Sierra, Xavier Andreu, Alejandro Camino, Begoña Barrera, Andrés Vicent y Violeta Ruiz sus comentarios y sugerencias. 
las dinámicas de género? Nuestras investigaciones apuntan hacia la necesidad de repensar radicalmente las visiones estándar de la masculinidad moderna, a menudo reducidas a un modelo estable y estático que opone la razón masculina con la emoción, siempre femenina. Las pasiones y los sentimientos, no exentos de contradicción, aparecen como elementos fundamentales a la hora de ejercer la profesión, pero también a la hora de construirse los médicos e ingenieros como hombres de ciencia dentro de la comunidad nacional. No es solo la contención de las pasiones mediante la razón lo que caracterizó la forma de la que estos hombres construyeron y experimentaron su masculinidad, sino el hecho de tener estas pasiones y usarlas de forma adecuada, provechosa para su patria y para la Humanidad.

Palabras clave: profesiones; ciencia; nación; masculinidad romántica; médicos; ingenieros.

ABSTRACT: In the mid-nineteenth century, Spanish physicians and engineers relied on the public dimensions of their professional activity in order to embody the new liberal masculinity. There were two ways of getting acknowledged as a part of liberal elites: first, the link to public institutions; second, the argument that their knowledge and skills contributed to the progress of civilisation and to common good. Exploring the link between usefulness and sciences, that had already been established already in the discourse of the Enlightenment, these men argued that their professions made them particularly useful for the country, as they contributed to make it wealthier and its inhabitants happier, but also to strengthen the position of Spain among the «nations of cultured Europe». What was the role of gender in this process? Did scientific professions have any features that were considered particularly masculine? How did class interact with gender? Our research points to the need to radically rethink the standard visions of modern masculinity, often reduced to a stable and static model that opposes masculine reason to emotion, always feminine. The passions and feelings, with all their contradictions, appear as fundamental elements in the professional practice of physicians and engineers, and also when these men constructed themselves as men of science within a national community. While the control of passions was indeed a defining feature of the way these men constructed and experienced their masculinity, so was having passions and using them the right way, to the benefit of the country and of the Humankind.

Key words: Professions; Science; Nation; Romantic masculinity; Physicians; Engineers.

En la España de mediados del siglo XIX, la masculinidad liberal se articuló ante todo alrededor de la propiedad y de la actividad en la esfera pública como un lugar de reconocimiento entre pares ${ }^{2}$. En este contexto, las profesiones consolidadas como los médicos y los juristas, y las que estaban en pleno proceso de definición, como los ingenieros y los científicos, desplegaron todo un abanico de estrategias discursivas y de

2. Sierra, María: "Política, romanticismo y masculinidad. Tassara (1817-1875)», Historia y Política, 27, 2012, pp. 203-226; SÁNCHEz León, Pablo: "La pesadilla mesocrática: ciudadanía y clases medias en el orden liberal histórico español». En Manuel Pérez Ledesma (ed.): De súbditos a ciudadanos. Una historia de la ciudadanía en España. Madrid: Centro de Estudios Políticos y Constitucionales, 2007, pp. 135-164; ArEsTi, Nerea y MARTYKÁNOVÁ, Darina: "Introducción: Masculinidades, nación y civilización en la España contemporánea”, Cuadernos de Historia Contemporánea, 39, 2017, pp. 11-17. 
prácticas para insertarse en las élites de la época. En tal que grupo social, las profesiones que se autodefinían como científicas se encontraban en una situación económica relativamente precaria en un momento en el que la ciudadanía activa estuvo restringida mediante criterios censitarios ${ }^{3}$ y el trabajo asalariado restaba honor y dignidad. Por lo tanto, no es de sorprender que los hombres que hicieron de la ciencia su sustento, exploraran las posibilidades de apoyarse en la actividad pública para encarnar eficazmente la masculinidad liberal. Las vías principales para hacerse reconocer como parte orgánica e influyente de las élites liberales eran dos. Primero, la vinculación con las instituciones del Estado en plena construcción. Segundo, el argumento de que su conocimiento y saber-hacer expertos contribuían decisivamente al progreso de la civilización y al bien común ${ }^{4}$. Si bien es cierto que el discurso de estos "facultativos» contenía elementos universalistas, como sus alusiones a la verdad científica y al amor a la Humanidad, la comunidad de referencia como sujeto del progreso y el bien común era, ante todo, la nación. Explorando el vínculo entre la utilidad y las ciencias, que había quedado establecido ya en el discurso de la Ilustración, estos hombres argumentaron que su profesión les hacía particularmente útiles para la patria, tanto a la hora de fomentar las riquezas del país y la felicidad de sus habitantes, como a la hora de contribuir a afianzar la posición de España entre las "naciones de la Europa culta». Esta preocupación, que, por una parte, enlazaba con la reivindicación de la contribución española a las ciencias que se había ido articulando desde el siglo XVII ${ }^{6}$, se vio acentuada por la creciente percepción entre las élites españolas de que su nación quedaba postergada en la jerarquía de prestigio dentro de las categorías como Europa u Occidente, tal y como se estaban configurando a nivel transnacional ${ }^{7}$.

¿Qué papel desempeñó el género en este proceso? ¿Hubo rasgos específicos de las profesiones científicas que las significaron como masculinas? ¿Cómo interactuó el factor de clase con las dinámicas de género? Los estudios existentes — centrados sobre

3. Sierra, María; PeÑa, María Antonia y ZuRITA, Rafael: Elegidos y elegibles: La representación parlamentaria en la cultura del liberalismo. Madrid: Marcial Pons, 2010.

4. Martykánová, Darina: "La profession, la masculinité et le travail. La représentation sociale des ingénieurs en Espagne pendant la deuxième moitié du XIXe siècle». En DEROUET, Antoine; PAYE, Simon y FraPIER Christelle (eds.): Les Ingénieurs. La production d'un groupe social. Tomo 1, París: Garnier, 2018, pp. 79-102.

5. Pino Díaz, Fermín del: «Utilidad y honor nacional en la política científica ilustrada». En FernÁNDEZ Pérez, J. y González Tascón, Ignacio (eds.): Ciencia, técnica y Estado en la España ilustrada. Madrid: Sociedad española de Historia de las ciencias y de las técnicas, 1990, pp. 31-43.

6. Cañizares-Esguera, Jorge: "Iberian Science in the Renaissance: Ignored How Much Longer?», Perspectives on Science, 12-1 (2004), pp. 103-105.

7. Bolufer, Mónica: “Orientalizing Southern Europe?: Spain Through The Eyes of Foreign Travelers». En The Eighteenth Century, 57, (4, 2016), pp. 451-467; Simal, Juan Luis y MARTYKÁNOvá, Darina: «Ferdinand and the Sultan: The Metaphor of the Turk and the Crisis of the Spanish Monarchy in the Early Nineteenth Century", Contributions to the History of Concepts, 10-1, 2015, pp. 1-26; ANDreu Miralles, Xavier: El descubrimiento de España: mito romántico e identidad nacional, Barcelona: Taurus, 2016. 
todo en el periodo desde el Sexenio Democrático hasta los primeros años del siglo $\mathrm{XX}$ - apuntan a que el trabajo, que en la historiografía sobre el género se considera tradicionalmente como clave en la redefinición de la masculinidad en el siglo XIX, era uno de los ejes más frágiles. Mientras los profesionales contribuyeron, junto con el movimiento obrero, a cuestionar la propiedad como base de la ciudadanía activa y reivindicaron con vigor el trabajo como una práctica moralizante para el hombre moderno, no lograron subvertir el discurso sobre los peligros de la degradación social asociada con el trabajo regular y asalariado, entendido como producto de una necesidad material y como creador de dependencia indeseable ${ }^{8}$. En cambio, nos encontramos con prácticas a las que la historiografía ha prestado poca atención y que parecen haber tenido una gran importancia a la hora de construir una profesión como masculina. Así, por ejemplo, la movilidad independiente por lugares potencialmente peligrosos, muy presente en el ejercicio profesional de los ingenieros y de algunas clases de médicos (los rurales especialmente) y resaltada en su discurso, era prácticamente irreconciliable con la feminidad respetable en la España decimonónica y aparece como un elemento importante en la significación como masculinas de estas profesiones.

En lo que concierne el conocimiento experto9 ${ }^{9}$ la base de las profesiones y de la función pública facultativa, se trataba de un conocimiento definido como aplicable y aplicado $^{10}$. Su lectura en clave de género constituye la parte más elusiva de nuestro

8. FeliPe, Jesús de: «Masculinidad y el movimiento obrero español: las identidades masculinas obreras y el trabajo femenino, 1830-1870", Historia, Trabajo y Sociedad, 8, 2017, pp. 65-85; SÁNCHEZ LEÓN, Pablo: "La pesadilla mesocrática...op. cit.; MARTYKÁNOvÁ, Darina: «La profession...”, op. cit.

9. El experto se definiría como alguien cuyos conocimientos y habilidades en cierta área son sustancialmente superiores a los de otras personas y, según reconoce su entorno, le confieren una mayor comprensión y capacidad de acción dentro de esta área. Esta categoría requería de una serie de características: formación, experiencia, neutralidad, noción de acción y, aunque con matices y diferentes grados, reconocimiento social de ese conocimiento experto. RABIER, Christelle: "Introduction. Expertise in Historical Perspective». En RaBier, Christelle (ed.): Fields of Expertise. A Comparative History of Expert Procedures in Paris and London, 1600 to Present. Newcastle: Cambridge Scholars publishing, 2007; BACKоuche, Isabelle: "Devenir expert", Genèses, 70, 2008, pp. 2-3; MARTYKÁNovÁ, Darina: «Las raíces de la tecnocracia: los ingenieros al servicio del Estado en España entre los 1780 y los 1830». En: Rodríguez-Arias, David, Maiso, Jordi y HeEney, Catherine (coords.): Justicia ¿Para todos? Perspectivas filosóficas. Madrid: Plaza y Valdés, 2016, pp. 161-172.

10. HaRwoOD, Jonathan: "Engineering Education between Science and Practice: Rethinking the historiography», History and Technology, 22-1, 2006, pp. 53-79; Gouzévitch, Irina y VéRIN, Hélène: «Sobre la institución y el desarrollo de la ingeniería: una perspectiva europea». En Silva SuÁREz, Manuel (ed.): Técnica e ingeniería en España. El Siglo de las Luces. De la industria al ámbito agroforestal. Vol. 3. Zaragoza: Real Academia de Ingeniería/Institución «Fernando el Católico»/Prensas Universitarias de Zaragoza, 2005 , pp. 115-163; Grelon, André y GouzÉvitch, Irina: «Reflexión sobre el ingeniero europeo en el siglo XIX: retos, problemáticas e historiografías». En SiLva SuÁREz, Manuel (ed.): Técnica e ingeniería en España. El Ochocientos. Profesiones e instituciones civiles. Vol. 4. Zaragoza: Real Academia de Ingeniería/Institución «Fernando el Católico»/Prensas Universitarias de Zaragoza, 2007, pp. 269-321. 
análisis ${ }^{11}$, hasta llevarnos a cuestionar algunas certezas sobre la vinculación entre la razón científica y la masculinidad en el siglo XIX. Las dudas que nos han ido surgiendo nos han llevado a retrotraernos a la primera mitad del siglo XIX y examinar los discursos profesionales en pleno proceso de configuración, a través de publicaciones especializadas (prensa profesional, obras científicas) y obras literarias. En este artículo presentamos algunas interpretaciones provisionales que hemos ido desarrollando al enfrentarnos con un panorama mucho más borroso de lo que sugieren las teorías más extendidas sobre la redefinición de la masculinidad a nivel transnacional, en el periodo de grandes cambios vinculados a las revoluciones constitucionales y a la revolución industrial. Nuestras investigaciones apuntan sobre todo hacia la necesidad de repensar radicalmente las visiones estándar de la masculinidad moderna, a menudo reducidas a un modelo estable y estático que opone la razón masculina con la emoción, siempre femenina. Las pasiones y los sentimientos, no exentos de contradicción, aparecen como elementos fundamentales a la hora de ejercer la profesión, pero también a la hora de construirse los médicos e ingenieros como hombres de ciencia dentro de la comunidad nacional. No es solo el control de las pasiones mediante la razón lo que caracterizó la forma de la que estos hombres construyeron y experimentaron su masculinidad, sino el hecho de tener estas pasiones y usarlas de forma adecuada, provechosa para su patria y para la Humanidad.

Por otra parte, no queremos dar a entender que estas dudas surgieran de una lectura independiente de las fuentes primarias. Los trabajos de María Sierra sobre el escritor y político moderado Tassara y sobre las obras de Bretón de los Herreros ya resaltaron que la noción de la masculinidad romántica pudiera tener un importante poder interpretativo ${ }^{12}$. Estos dos trabajos de Sierra muestran no solo los amplios espacios de maniobra que existían a la hora de negociar y legitimar la variedad en las relaciones de género, sino también el peso que tenía la gestión de las pasiones en la definición de la masculinidad de las élites españolas en las primeras décadas del periodo liberal, ya que a los hombres en absoluto se les consideraba ajenos a la fuerza de las emociones. Cabe añadir que la integración orgánica de los sentimientos en la masculinidad de las élites no fue, bajo ningún concepto, exclusiva de España, sino que se observa, con matices, en otros países europeos y americanos ${ }^{13}$. En general, creemos

11. A lo largo del texto dialogamos con algunos planteamientos sobre las «masculinidades científicas» del dosier Milam, Erika L. y Nye, R.A. (eds.): «Scientific Masculinities». En Osiris, 30, 2015 particularmente Milam, Erika L. y NYe, Robert A.: "An Introduction to Scientific Masculinities», Osiris 30, 2015, pp.1-14.

12. Sierra, María: "Política, romanticismo y masculinidad...op. cit.; Sierra, María (ed. lit.): Género y emociones en el romanticismo. El teatro de Bretón de los Herreros. Zaragoza: Institución Fernando el Católico, 2013.

13. Algunos ejemplos: Gutermann-JACQuet, Deborah: Les équivoques du genre. Devenir homme et femme à l'âge romantique, Rennes: Prresses universitaires de Rennes, 2012; CHAPMAn, Mary y HendLER, Glenn (eds.): Sentimental Men: Masculinity and the Politics of Affect in American Culture, Berkeley, Los Ángeles/ Londres: University of California Press, 1999. Elementos románticos se aprecian también en la cultura política 
que hay que poner en duda la tendencia de proyectar las pautas que caracterizaron la masculinidad de las élites finiseculares hacia mediados del siglo XIX y hacia las décadas anteriores, lo que puede ocurrir al usar la categoría genérica de «masculinidad liberal» sin matices y sin contemplar los cambios a lo largo del siglo. Nuestro propósito es ahondar en esta línea en el campo de la historia de las profesiones, incentivados por la observación de Mercedes Arbaiza sobre los cambios en la representación de la medicina en la literatura española y de Fernando Sáenz Ridruejo sobre los cambios en los mapas, diseños y proyectos elaborados por los ingenieros de caminos, cambios que ambos caracterizan como paso de una visión romántica de las respectivas «ciencias» hacia una visión "positivista" de las mismas ${ }^{14}$. Sin pretender imponer una periodización inflexible, queremos explorar cómo se redefinió durante la era de las revoluciones y de la construcción de los estados-nación el ideal ilustrado del hombre de ciencia como un hombre sensible hacia una figura romántica que unía la utilidad a la patria con el amor a la humanidad. Rastreamos también los comienzos de la configuración de una noción de científico más positivista y desapasionado que iba a consolidarse a finales del siglo XIX.

\section{HOMBRES DE EDUCACIÓN NO VULGAR}

Las profesiones científicas no tenían el mismo grado de consolidación en cuanto al vínculo con una formación específica, a la implantación y reconocimiento estatal y social y a la existencia de instituciones propias. Los médicos contaban con un entramado institucional consolidado y con una representación social potente desde hacía siglos, si bien es cierto que a lo largo del siglo XIX, tanto las instituciones médicas como la imagen del médico en el imaginario social iban a sufrir grandes transformaciones $^{15}$. López Piñero definió el siglo XIX como periodo de crisis y de transición en la

legitimista española y transnacional: VICENT, Andrés: De la Monarquía Católica a la Europa legitimista: una bistoria transnacional del primer carlismo, tesis doctoral, Madrid: Universidad Autónoma de Madrid, 2019.

14. SÁenz Ridruejo, Fernando: Los ingenieros de caminos. Madrid: Colegio de Ingenieros de Caminos, Canales y Puertos, 1993. Mercedes Arbaiza apunta a la validez para el caso español de las pautas de evolución de la (auto)-representación de los médicos a nivel transnacional en Arbaiza, Mercedes: "Perder el miedo a Dios». Masculinidad moderna y emoción liberal en España (1900-1931) a través de relatos literarios", Comunicación presentada al taller: «Ser hombre» como problema: género, clase y nación en la construcción de las masculinidades modernas", XIV Congreso de la Asociación de Historia Contemporánea, Alicante, 20-22 de septiembre de 2018. Para el Reino Unido véase: https://emotionsblog.history.qmul.ac.uk/2016/04/representingemotion-in-the-doctor-patient-encounter-in-victorian-medical-writing/ y, para Centroeuropa, LENDEROVÁ, Milena, Tinková, Daniela y Hanulík, Vladan (eds.): Tělo mezi medicínou a disciplinou. Promèny lékařského obrazu a ideálu lidskébo těla a tělesnosti v dloubém 19. století. Praga: Nakladatelství Lidové noviny, 2014.

15. Martykánová, Darina y NúÑez García, Víctor M.: "Luces de España: las 'ciencias útiles' durante el Trienio constitucional», Ayer (en prensa). 
medicina española entre dos etapas de expansión científico-médica, el periodo ilustrado y la medicina positivista del final del siglo XIX ${ }^{16}$. En este periodo además se articuló un discurso profesional a través de la prensa médica en esta etapa (El Siglo Médico, Unión Médica, España Médica, El Porvenir Médico...), que contribuyó de forma clave a redefinir el papel de las profesiones sanitarias (farmacia, medicina y cirugía, hasta la unificación de las dos últimas) en la sociedad liberal.

Según como lo plantearon los propios médicos, para ejercer bien el arte de curar se requería una formación mucho más allá de "la ciencia médica»:

No bastan pocos años para adquirir las disposiciones precisas en las ciencias auxiliares. La gramática general y en particular la griega y la latina, con la de los idiomas vivos más usados, la retórica, elocuencia, y poesía; la ideología, la lógica, las matemáticas, física experimental, la geografía, el dibujo, la botánica, la química, y la filosofía moral, son los elementos preparatorios para entrar con alguna esperanza de hacer frutos en la ciencia médica ${ }^{17}$.

Sin embargo, ni siquiera esta ya de por sí amplísima formación resultaba suficiente. La autorrepresentación de los médicos durante la primera mitad del siglo XIX en continuidad con las décadas anteriores, incluía de forma explícita cualidades y habilidades que no se entendían como derivadas de la instrucción en ciencias y artes, sino que se percibían como rasgos personales (aptitud mental, bondad de corazón) y de clase (bien nacido y educado):

en vano emprenderá esta ciencia el joven que, a más de bien nacido y educado, no cuente con un fondo de aptitud mental, y una bondad de corazón capaz de resistir a duras pruebas ${ }^{18}$.

Ciertas cualidades difíciles de medir eran imprescindibles no solo para adquirir todos los conocimientos necesarios y para curar bien, sino también para dejar buena impresión en los pacientes. Allí, el proceder de cada médico repercutía en la reputación de toda la profesión, igual que el comportamiento de un ingeniero de Estado podía reforzar o socavar el «honor del cuerpo». La prensa profesional ofrecía recomendaciones para que los médicos supieran hacer bien los escritos que se daban a los enfermos en las consultas, preocupada por el hecho de que las incorrecciones en la redacción provocaran el «descrédito en todo el cuerpo de profesores».

16. López PIÑERo, José María: «Las ciencias médicas en la España del siglo XIX», Ayer, 7, 1992, pp. 193-240.

17. «Exposición del mérito y premio de la medicina comparado con el de las demás ciencias y otros ramos del Estado, en el año de 1820 (el 26 de julio de 1820). Por el doctor don José Francisco Pedralbes, médico de Cámara honorario de S.M.» Décadas médico-quirúrgicas, tomo 1, nº 2, 1820, pp. 66-75.

18. Ibid. 
La causa principal de imperfección consiste en que no ha reflexionado bien cada uno sobre las cualidades que deben distinguir este escrito, el cual exige conocimientos prácticos muy extensos, mucho método, un lenguaje de cierta forma, un estilo acomodado a las personas a quienes se dirige, y sobre todo una circunspección muy grande ${ }^{19}$.

Si bien los médicos necesitaban de cualidades y habilidades que denotaran distinción profesional y social e impresionaran a sus pacientes, el ejercicio de la medicina cultivaba en el que la practicaba, según los médicos, cualidades como la heroicidad, la ilustración y la beneficencia, sublimando el carácter del hombre:

Ésta pide a más conocido talento, incansable aplicación, y un genio particular tan fecundo en ideas como en virtudes. Entre los médicos, el que no es héroe, no es nada: esta ciencia no tolera la mediocridad. Su ejercicio sublima el carácter del hombre, elevándote al máximum de la humanidad, por sumas que pide de ilustración y beneficencia. Su saber es solo para bien de los demás; su trabajo mira exclusivamente, el consuelo, del prójimo ${ }^{20}$.

Resaltemos el énfasis en los médicos como esencialmente altruistas, preocupados en el bien de los demás. Presentarse como "desinteresados», movidos por el "amor a la Humanidad", no resultaba incompatible con reclamar al Estado cargos de poder y garantías de una buena remuneración. Es más, servía como argumento para hacerlo, al vincular el reconocimiento y el alto estatus de los profesionales de la medicina con la ilustración de la nación y el lugar que ocupaba España entre los países civilizados:

¿Y será posible que unos individuos tan beneméritos y consagrados al primero de los objetos por su importancia, al más arduo por sus dificultades y privaciones, al más triste por sus escenas y resultados, se hallen pospuestos y abatidos en España, en el siglo XIX que se jacta de ilustración y humanidad? La humanidad y la ilustración de toda Europa brilla señaladamente en los médicos, como es de ver en sus obras. Así también las naciones más adelantadas les colocan en los primeros puestos del estado ${ }^{21}$.

El caso de los ingenieros es bien distinto. A pesar de existir en la Monarquía católica una tradición potente en ingeniería hidráulica y militar datada al menos desde el Renacimiento, en España no se puede hablar de la ingeniería en términos de una profesión hasta los años 1840. En la primera mitad del siglo XIX, la palabra ingeniero solía hacer referencia a los ingenieros del Ejército, sin que el que la usó sintiera la necesidad de añadir "militar» $\mathrm{O}$ "del Ejército". La figura del ingeniero de caminos como un facultativo civil al servicio del Estado había surgido a finales del siglo XVIII y languideció desde los

19. Repertorio Médico Extranjero, tomo 5, no 2, 1835.

20. «Exposición del mérito y premio de la medicina comparado con el de las demás ciencias y otros ramos del Estado, en el año de 1820 (la fecha es el 26 de julio de 1820). Por el doctor don José Francisco Pedralbes, médico de Cámara honorario de S.M.» Décadas médico-quirúrgicas, tomo 1, n 2, 1820, pp. 66-75.

21. Ibid. 
finales de la primera década del XIX. En el Trienio constitucional (1820-1823) se dieron pasos importantes para recuperarla, pero la segunda restauración fernandina truncó este proceso quedando cerrada la Escuela de caminos, mientras que el cuerpo languidecía en número de personal y en financiación y los ingenieros solo pudieron consolidarse como empleados públicos facultativos a partir de mediados de los $1830^{22}$. Si bien es cierto que en varios países se abría camino la figura del ingeniero civil en el sentido de un profesional que presta sus servicios a compañías y particulares, y los españoles eran conscientes de la existencia de esta figura, en España apenas hubo hombres que se definieran así hasta los años 1830, y los que hubiera solían ser extranjeros.

Mientras que la figura del ingeniero como militar se había ido consolidando en España, igual que en Francia, el Reino Unido, Portugal y Rusia, a lo largo del siglo XVIII, el periodo 1790-1840 corresponde al momento de la redefinición de la figura del ingeniero al servicio del soberano, fuera de las estructuras militares, que iba a marcar profundamente la consolidación de la ingeniería como profesión en la España de mediados del siglo XIX ${ }^{23}$. Esta figura surgió en el marco del discurso de fomento, entendido como acción del gobierno y de las élites patrióticas dirigida a estimular la producción y el comercio con el objetivo de generar mayor riqueza y más recursos para el Estado. El momento de definición de la ingeniería dentro de la Administración civil es fundamental para identificar algunas de las características que iban a definir la profesión de ingeniero en España en las décadas por venir. Al mismo tiempo, apropiarse de algunos elementos particulares de la masculinidad hegemónica de la época -como veremos a continuación - permitió a los hombres identificados como ingenieros negociar su posición entre las élites sociales.

En su Memoria sobre los medios de facilitar el comercio interior (1791), Agustín de Betancourt y Juan López de Peñalver, dos hombres de ciencia de renombre, que habían sido becados por la Corona para llevar a cabo una serie de tareas tecnocientíficas en distintos lugares de Europa, describieron como debía ser un «director de caminos». Se trataba de un cargo directivo perteneciente al entramado institucional de carácter civil (no-militar) que debería, en su opinión, crear la Corona para mejorar, construir y mantener en buen estado las carreteras y los puentes en España, ampliando y reforzando algunas instituciones existentes desde los 1770).

22. Silva Sú́rez, Manuel y Lusa Monforte, Guillermo: "Cuerpos facultativos del Estado versus profesión liberal». En Silva Suárez, Manuel (ed.): Técnica e ingeniería en España. El ochocientos: pensamiento, profesiones y sociedad. Vol. 4. Zaragoza: Real Academia de Ingeniería/Institución 'Fernando el Católico'/ Prensas Universitarias de Zaragoza, 2007, pp. 323-386.

23. GRelon, André y Gouzévitch, Irina: «Reflexión sobre el ingeniero europeo... op. cit.; GouzÉvitch, Irina; Cardoso de Matos, Ana; MartykÁnovÁ, Darina: «La Russie, l'Espagne, le Portugal et l'Empire ottoman: deux siècles de politiques technoscientifiques à l'épreuve des approches comparatistes». En KLEICHE-DraY, Mina (ed.): Les ancrages nationaux de la science mondiale, XVIIIe-XXIe siècles, París/Marsella: EAC/IDR, 2017, pp. 239-286. 
[debe]...haber hecho un estudio sólido de geometría y trigonometría, con sus aplicaciones a la práctica; saber el uso de los mejores instrumentos para levantar los planos; medir distancias y alturas; nivelar un terreno; calcular con facilidad y exactitud los desmontes y terraplenes; delinear y lavar un plano, para poder representar un proyecto con claridad; conocer los materiales que corresponden a cada clase de obras, y la resistencia de las piedras por principios ciertos; saber los varios métodos de fundar en el agua, en un terreno de arena, de tierra o peña, para aplicarlos según las circunstancias; estar instruido de las diferentes especies de puentes que se han imaginado, ya de madera, de piedra o de hierro, para ejecutarlos donde convenga; tener noticia de las muchas máquinas que se han inventado para trabajar con economía en los puentes y caminos; saberlas variar o modificar, según lo exijan los varios casos en que se han de emplear; poder juzgar con seguridad cuándo se debe preferir el trabajo de los hombres al de los animales o el de éstos al de aquellos; calcular las causas políticas que deben influir en la dirección que se puede dar a un camino. En fin, permítasenos decirlo, tener una educación no vulgar, la cual no solamente hace recomendables los hombres en el trato con los demás, sino que también da aquel discernimiento y aquel tacto fino que en ciertos casos suele servir aún más que la ciencia. Tales son las circunstancias que deben concurrir en un director de caminos ${ }^{24}$.

En esta propuesta llaman la atención varios detalles. En primer lugar, destaquemos que el cargo no se vincula con una formación estandarizada, con una carrera establecida. El campo de expertise (conocimiento y habilidades) de los ingenieros era todavía borroso, al no existir un entramado institucional que lo estabilizara. Por eso los autores tuvieron que exponer en detalle qué tipo de conocimientos y habilidades preveían en un director de caminos. Podemos apreciar que se trataba tanto de conocimientos obtenidos mediante el estudio como de habilidades obtenidas mediante la práctica, muy probablemente supervisada. Además, se esperaba que los directores supieran afrontar las tareas de gestión, incluido el trato con los subalternos y también, implícitamente, con los superiores. En general, se buscaba que fueran hombres del mundo capaces de moverse en la jerarquía del servicio al Soberano, y al mismo tiempo, tuvieran una visión sobre el contexto geopolítico. Al definir Betancourt y Peñalver la formación requerida en su conjunto como «educación no vulgar,» no solamente reclamaron unos conocimientos y habilidades de carácter experto, sino al mismo tiempo movilizaron un imaginario de clase y de género, mediante referencias a características difíciles de medir (capacidad de mando, buen juicio, buen criterio, tacto fino). De este modo, presentaron el cargo como una ocupación digna de un caballero, como fueron ellos mismos. Resaltemos además que esta «educación no vulgar» hacía a estos hombres dignos del aprecio - y de emulación - de sus pares (es decir, otros varones de su clase), un requerimiento

24. Betancourt, Agustín de y LóPez Peñalver, Juan: «Memoria sobre los medios de facilitar el comercio interior, 20 de junio de 1791", texto reproducido en Lluch, Ernest (ed.): Escritos de López de Peñalver, Madrid: Instituto de Cooperación Iberoamericana/ Instituto de Estudios Fiscales, 1992, pp. 5-32. 
que, como veremos más adelante, iba a considerarse un imperativo de la masculinidad a lo largo de la época.

¿Cuáles de estas características fueron significadas como masculinas en aquella época? ¿Cuáles, aun pudiendo darse en una mujer, se consideraban signo de una masculinidad deseable? En principio, en una visión jerárquica de los sexos, a los hombres se les presuponía una mayor capacidad para el uso de la razón y, por ende, el mejor dominio de las ciencias. Sin embargo, era asumible que las mujeres excepcionales pudieran usar la razón de forma eficaz y destacar por sus conocimientos, hasta por la práctica científica. La República de las Letras transimperial que se extendía por Europa, el Mediterráneo y América, incluyendo asimismo núcleos de producción y sociabilidad científica en otros lugares del planeta, fue capaz de integrar tanto a los hombres, como a las mujeres, si ostentaron ciertas características (sobre todo de clase) y desarrollaron eficazmente una serie de prácticas (debate distendido con sus pares, integración en las redes de correspondencia, actividades intelectuales plasmadas en publicaciones) ${ }^{25}$. Es cierto que los saberes de los ingenieros, un término que en la España de la época aparecía vinculado ante todo con militares, constructores de navíos y expertos en obras hidráulicas, incluían algunas prácticas que, al ser asociadas con el arte de la guerra y grandes obras al aire libre, fueron significadas claramente como masculinas. En nuestra opinión, la violencia legítima ("el arte de la guerra») y la movilidad libre (no vigilada y supervisada) por el espacio público fueron características que fueron incompatibles con la feminidad respetable en la España del siglo XVIII e iban a seguir siéndolo durante la primera mitad del siglo XIX ${ }^{26}$.

Además, el carácter incuestionablemente masculino de la ingeniería militar y civil tal como se estaba reconfigurando en España en aquella época, estaba ligado a la significación como masculino del servicio facultativo a la Corona en general. Tanto los cuerpos del Ejército y de la Armada, respectivamente, como los nuevos cuerpos civiles, formaron parte de un entramado de instituciones (cuerpos, regimientos, secretarías, colegios, etc.) y prácticas (formalización de la formación mediante la relación maestro-aprendiz, exámenes, escalafón) que había ido reforzando la masculinización

25. KNotT, Sarah y TAYLOR, Barbara (eds.): Women, Gender and Enlightenment. Palgrave Macmillan, 2005; FindLEN, Paula: "Science as a Career in Enlightenment Italy: The Strategies of Laura Bassi», Isis, 84-3, 1993, pp. 441-469; Serrano, Elena: "Chemistry in the city: The scientific role of female societies in late eighteenth-century Madrid», Ambix, 60-2, 2013, pp. 139-159; SERRANo, Elena: "Mujeres y Ciencia en la España de la Ilustración", Investigación y Ciencia, 2015, pp. 40-41.

26. Las dinámicas de la feminidad respetable en los siglos XVIII y XIX están tratadas de forma muy sugerente en las obras de Mónica Bolufer y Mónica Burguera, por ej.: Bolufer, Mónica: «Femmes et hommes dans la société idéale: les 'Sociétés économiques des amis du pays' dans l'Espagne des Lumières", Dix-buitième siècle, 43, 2011, pp. 487-504; "Mujeres y hombres en los espacios del reformismo ilustrado", Revista HMiC: història moderna i contemporània, 1, 2003, pp. 155-170; Mónica BurguerA, Las damas del liberalismo respetable, Madrid: Cátedra, 2012. 
del gobierno desde la Edad Moderna, dejando fuera a las mujeres de estos nuevos ámbitos del poder institucionalizado, aunque éstas siguieran ocupando espacios en los que prevalecía el principio de sangre y la lógica de la casa aristocrática ${ }^{27}$.

La estandarización de la formación de los ingenieros en las escuelas especiales militares y civiles, creadas y gestionadas por el Estado, se inscribe en este proceso de institucionalización que culmina a mediados del siglo XIX y reafirma la ingeniería como una carrera masculina. Al mismo tiempo, esta nueva masculinidad post-aristocrática encarnada en el facultativo al servicio del Estado se construía mediante un proceso formativo que, de nuevo, incluía elementos más allá de la capacidad de mando y de la transmisión de conocimientos y habilidades técnicas y científicas. Entre ellos destacaban la uniformidad de ideas y el espíritu del cuerpo:

A pesar de estos ventajosos resultados no era posible desconocer que si el sistema de escuelas generales podía en realidad proporcionar buenos Oficiales de Ingenieros, distaba mucho de ser bastante eficaz para desenvolver y consolidar aquel espíritu de cuerpo tan provechoso para el Estado como para los individuos, cuando va noblemente encaminado, y que solo se puede crear en un establecimiento especial de enseñanza dando unidad a la instrucción, intimidad a las relaciones y una dirección común a las ideas y tendencias de los que aspiran a servir en una misma carrera ${ }^{28}$.

La unidad de pensamiento y estilo, plasmada en el concepto del «espíritu del cuerpo", el compañerismo igualitario entre los aspirantes y el respecto a la jerarquía del cuerpo fueron elementos constitutivos de esta hermandad establecida durante un periodo de convivencia intensa como fue la instrucción en las escuelas especiales, civiles y militares.

[La Escuela de Caminos], con su sencillez espartana y severidad de claustro, con su noble emulación y sus campañas laboriosas, duro gimnasio de la inteligencia y piedra de toque de la constancia, templa para siempre las fibras de la voluntad y de la acerada lógica, que no se doblará ante el sufrimiento, e infunde en el alma una especie de filosofía que hace desdeñar ciertas miserias ${ }^{29}$.

Estas y otras pautas, características del funcionamiento de las escuelas y de los cuerpos sobre todo a partir de los 1840, fueron moldeando a los que pasaron por estas instituciones hasta que llegaran a encarnar un modelo de masculinidad que se diferenciaba

27. BuRdiel, Isabel: Isabel II. Una biografía (1830-1904), Madrid: Taurus, 2010; SAN NARCISO, David: "Mujeres en Palacio, Señoras en Política. El poder informal femenino en la corte de Isabel II, 1833-1868", Cuadernos de Historia Contemporánea, 40 (2018), pp. 129-147.

28. Resumen bistórico del arma de ingenieros en general, y de su organización en España, por un antiguo Oficial del Cuerpo de Ingenieros del Ejército, que desempeña boy un alto cargo en otra carrera, Madrid: Imprenta Nacional, 1846. Reproducido en Memorial de Ingenieros, 1-9 (1846), 118-119.

29. B.M.: "El ingeniero de Caminos," Revista de Obras Públicas, 5, 1875, p. 55. 
del caballero de la ciencia romántico. Se trataba de una síntesis interesante entre los rasgos resignificados de los organismos militares y eclesiásticos del Antiguo Régimen, por una parte, y, por la otra, la estandarización de conocimientos y prácticas, la disciplina entendida como racional y, por eso, interiorizada libremente y mantenida sin control externo, y la acción colectiva en la opinión pública, características de los empleados del Estado moderno ${ }^{30}$. Algunas de estas pautas de funcionamiento iban a convertirse en el ariete con el que las mujeres fueron conquistando las profesiones de alto estatus: ante todo, el conocimiento científico estandarizado y demostrable mediante procedimientos entendidos como «meritocráticos», sobre todo los exámenes y las oposiciones.

La institucionalización y regulación legal caracterizadas en España, de forma parecida a Francia, por el gran peso de las escuelas y cuerpos estatales accesibles solo a los hombres que ostentaran la nacionalidad española, reforzó la noción de una comunidad nacional de ingenieros españoles, en una época que, por otra parte, se caracterizaba por la presencia de numerosos técnicos extranjeros en el país, incluso por la posición privilegiada de estos en el sector privado, y por una gran movilidad de ingenieros a nivel mundial. La República de las Letras se fue transformando en una comunidad internacional de expertos que habían adquirido sus credenciales en instituciones de marcado carácter nacional que, además, se empezaron a preocupar por excluir a las mujeres de forma explícita — por ejemplo mediante leyes y reglamentos que limitaban el acceso a los cargos públicos y a las instituciones (incluidas las escuelas de estudios superiores) a los varones - al mismo tiempo que reforzaban las prácticas entendidas como impersonales y meritocráticas.

\section{LOS AMANTES DE LA HUMANIDAD}

Mientras que la ingeniería se desarrolló en sus distintas especialidades ante todo como una carrera del Estado, el campo experto de la salud estaba dominado por «las tres profesiones de la ciencia de curar»: medicina, cirugía y farmacia. La consolidación y el reconocimiento profesionales se vieron reforzados por una representación social de la práctica médica que contaba con una larguísima tradición y con una amplia difusión social. Además, la profesión médica se apoyaba en una formación estandarizada e institucionalizada desde hacía siglos en las universidades. La formación de cirujanos y farmacéuticos alcanzó un alto grado de institucionalización en el siglo XVIII al inaugurarse los reales colegios, como el Real Colegio de Cirugía de San Carlos de Madrid en $1771^{31}$.

30. Malatesta, Maria: Professionisti e gentiluomini: storia delle professioni nell'Europa contemporánea. Torino: Einaudi, 2006.

31. Burke, Michael E.: The Royal College of San Carlos. Durham: Duke University Press, 1977. 
Eso no significa que en la medicina no se diera la batalla por dominar el campo y determinar las reglas de acceso, una batalla que se basaba precisamente en la exclusión de las mujeres o en su subordinación a los médicos. Hay una amplia bibliografía que trata las particularidades de este proceso en muchos países y regiones del mundo en los siglos XVII-XX ${ }^{32}$. A diferencia de algunas otras actividades profesionales, en el caso de la medicina no se trataba de significar el arte de curar como esencialmente masculino, ya que siempre había sitio en él para las mujeres (matronas, enfermeras, cuidadoras), sino establecer una jerarquía clara cargada de nociones de género en la que sólo los hombres dotados de ciertas características pudieran ejercer la autoridad máxima. Para afianzar la representación de la profesión como científica y al mismo tiempo inscribirla firmemente entre las ocupaciones dignas de un caballero, los médicos desplegaron un gran esfuerzo retórico e institucional para excluir a varones subalternos, sin estudios universitarios ni otros estudios superiores, e incluso a médicos cuyas prácticas se consideraron degradantes para el prestigio de la profesión. Movilizando el concepto de charlatán, los profesionales del arte de curar emplearon las categorías de género para estigmatizar y marginar a estos hombres. Lo hicieron presentándoles en términos de hipomasculinidad ${ }^{33}$, es decir, una masculinidad insuficiente, cuestionando su capacidad de usar la razón, al presentarlos como ignorantes de la medicina científica y como entregados a la superstición, además de atribuirles la avaricia y la debilidad moral. Sin embargo, esta representación crítica incluía también elementos de la hipermasculinidad delictiva - la manifestación desmedida e inapropiada de rasgos y atributos viriles, al ser acusados estos «charlatanes» de seducir a las pacientes crédulas con su palabrería y sus terapias fraudulentas. Es decir, se les presentaba como aquellos que abusaban del dominio legítimo sobre las mujeres y sobre los pacientes en general, una operación retórica que, al mismo tiempo feminizaba la figura del paciente y reforzaba la masculinización simbólica de la profesión médica ${ }^{34}$.

En la siguiente cita se despliegan estas pautas, al mismo tiempo que se lleva a cabo una reafirmación del carácter nacional español como particularmente masculino,

32. Sobre las dinámicas que caracterizaron la actividad sanadora de las mujeres europeas a largo plazo y sobre la los esfuerzos eficaces de masculinizar la medicina en los siglos XVIII y XIX destaca el dosier coordinado por Montserrat CABRÉ y Teresa OrTIZ-GÓMEZ, «Mujeres y Salud: Prácticas y Saberes / Women and Health: Practices and Knowledge», Dynamis 19 (1999).

33. Kimmel, Michael: "Masculinidades globales: restauración y resistencia», Masculinidades globales: restauración y resistencia. En SÁnchez-PALEncia, Carolina y Hidalgo, J.C. (eds.): Masculino Plural: Construcciones de la masculinidad, Lleida: Universitat de Lleida, 2001, pp. 47-75. Desarrollado en MARTYKÁNOVÁ, Darina: «Los pueblos viriles y el yugo del caballero español. La virilidad como problema nacional en el regeneracionismo español (1890s-1910s)», Cuadernos de Historia Contemporánea, 39, 2017, p. 21.

34. Gelfand, Toby: «Medical Professionals and Charlatans. The Comité de Salubrité Enquête of 179091", Social History 11, 1978, pp. 62-97; Hanulík, Vladan: "Apoštol i šarlatán. Zakladatel hydropatie Vincenz Priessnitz», Déjiny a současnost, 8, 2007, pp. 37-39. 
al tender supuestamente los españoles a la honradez, sobriedad y seriedad, frente a los extranjeros, construidos como proclives al engaño y a la charlatanería:

Todo el mundo conoce al doctor del Agua azul. Este médico amable, é ingenioso, encanto del bello sexo, adorno de los estrados, y que hubiera podido ser el de la medicina, ha experimentado un ligero disguste que los lectores acaso no podrán escuchar sin reírse. El doctor Z . . . ha cultivado mucho un género de enfermedades, y se ha adquirido una justa celebridad y aun la confianza de sus comprofesores.

\section{[...]}

Aunque el público y gobierno Español no recompensa ni considera á los profesores del arte de curar tan ventajosamente como lo hacen los extranjeros con los suyos, son muy, raros estos casos de codicias, bajezas y charlatanerías entre nuestros facultativos. En efecto, para un médico, cirujano ó boticario español que abuse del título que le concede la ley, que hasta cierto punto no puede impedirle ejercer la mala fe ó el charlatanismo, hay ó se ven cinco ó seis entre los extranjeros, á pesar de la gran vigilancia de un consejo de sanidad ó policía médica de que carecemos en España ${ }^{35}$.

El discurso médico contra la charlatanería tuvo continuidad en las décadas siguientes. Por ejemplo, en los años 1850 se inició desde la prensa profesional médica una campaña de denuncia frente al intrusismo y mala praxis profesional bajo el epígrafe "títulos falsos o falseados», no sólo por lo pernicioso para la búsqueda de prestigio social de estas profesiones, sino por el daño que estas prácticas irregulares hacían a la imagen de España como país civilizado. Todo ello menoscababa «la reputación del gobierno de un pueblo culto ${ }^{36}$.

Las acusaciones de la falta de honradez y de seriedad, además de la negación de las aptitudes expertas se repiten también en el discurso de los ingenieros a la hora de denunciar el intrusismo de hombres sin formación superior, sobre todo cuando obtenían puestos dignos de caballero usando credenciales dudosas adquiridas en el extranjero. El reto consistía en marcar la diferencia con hombres que se movían en los márgenes de la respetabilidad burguesa reclamando para sí la denominación de ingeniero, más que en establecer una frontera clara entre el ingeniero y el operario, una pugna que sí se dio en otros contextos históricos y culturales ${ }^{37}$. En general, en España en la época que aquí analizamos, el hombre «bruto» como el Otro radical de estos hombres de ciencia que se percibían como caballeros, parecía estar bien domado

35. Décadas médico-quirúrgicas, tomo 1, n 2, 1820, pp. 76-77.

36. El Siglo Médico, 1-1-1854.

37. Silva SuÁrez, Manuel y Lusa Monforte, Guillermo: “Cuerpos facultativos...”, op. cit.; MarTYKÁNOVÁ, Darina: "Shaping a New Man: The Schools for the State Engineers in Nineteenth-Century Spain (1830s-1900)», Engineering Studies, 7, 2014, pp. 87-107. 
en el espacio que le fue asignado: el del trabajo manual, que además le «embrutecía» irremediablemente, legitimándose así su subalternidad ${ }^{38}$.

Eran los rivales de la misma clase los que sufrieron una feminización discursiva. La oposición entre la laboriosidad de los médicos e ingenieros, por una parte, y la ociosidad de otros hombres de su clase conectaba con la crítica ilustrada de la ociosidad, pero no interpelaba necesariamente a los hombres de élite sin profesión conocida (terratenientes, rentistas), sino sobre todo a aquellos que no eran activos de forma productiva, fuese en la vida política o en sus actividades económicas. Es más, algunas profesiones de élite más consolidadas, como arquitectos y, sobre todo, abogados, fueron sometidas a duras críticas, oponiéndose su supuesto ornamentalismo, palabrería vacía y falta de utilidad social a lo duro y penoso de la formación y del ejercicio profesional de los ingenieros y médicos, y, sobre todo, a su incuestionable servicio al bien común ${ }^{39}$. La crítica de los militares, presente en la época entre los médicos y los ingenieros, solía incluir el reconocimiento de su valor y utilidad y reclamar la reciprocidad en el aprecio, más que cuestionar su posición ${ }^{40}$.

Si bien es cierto que la laboriosidad, la seriedad y la sobriedad fueron, junto con la honradez, algunas de las características que los médicos y los ingenieros en las décadas de 1820-1860 se atribuyeron a sí mismos frente a los charlatanes, malos profesionales y a otras profesiones con las que en un modo u otro tendían a rivalizar (abogados, arquitectos), no debemos presuponer que se construyeron a sí mismos en términos de una racionalidad fría, como desapasionados o carentes de sentimientos. El discurso de estos hombres de ciencia románticos está cargado de pasión, las emociones están a flor de piel. Es más, sentirlas y manifestarlas se consideraba, de hecho, central para un buen ejercicio de la profesión. Un médico debería ser un hombre "sensible y pundonoroso» e inspirar a los otros «...más con su ejemplo que con sus palabras las virtudes propias del verdadero médico, que son la serenidad, la dulzura, el desinterés, la moderación, el candor y la humanidad... ${ }^{41}$. El amor a la verdad, considerado inherente a todos los humanos, constituía un elemento clave del progreso de las ciencias:

38. J.M.D.: «Sobre los principales depósitos auríferos y en particular sobre los de la California», Revista Minera, 2, 1850, pp. 56-61.

39. La utilidad incuestionable: «La medicina, como todas las demás ciencias, estriba en algunas verdades palpables, que no son propiedad exclusiva de ningún pueblo ni de ningún particular, sino que pertenecen a la humanidad entera [...] son otras tantas verdades que en aquellas ciencias, y en las médicas, se pueden llamar primordiales, y pertenecen al sentido común, a la recta razón, porque todo el mundo las reconoce sin necesidad de demostración, y sin que dejen de ser tan evidentes para el ignorante como para el sabio». Repertorio Médico Extranjero, tomo 5, no 2, 1835, s.p.

40. P.: «Observaciones sobre el decreto expedido por el gobierno portugués disolviendo el Cuerpo de Ingenieros Civiles", Revista de Obras Públicas, 24, 1868, pp. 281-284.

41. Décadas médico-quirúrgicas, tomo 1, n² 2, 1820, pp. 60-61. 
¿Se funda sobre abstracciones o ficciones, o sobre hechos positivos y materiales? He aquí toda la cuestión. Si se funda sobre ficciones, en vano habrá brillado por algunos instantes con un esplendor sin igual: el amor de la verdad, esta necesidad de todas las almas, triunfará bien pronto del amor de la novedad ${ }^{42}$.

De hecho, los médicos y los ingenieros, militares y civiles, presentaron la práctica científica en general como una actividad motivada por el «fuego sagrado del amor a la ciencia "43 y por la búsqueda de la gloria, lejos del imaginario positivista con el que nos encontramos a finales del siglo XIX: «algunos sabios, adornados de las luces y conocimientos del día, y excitados de la gloria y amor á las ciencias físicas, se han dedicado espontáneamente á investigar y conocer muchos de los objetos que la naturaleza ha producido.... ${ }^{44}$.

El ejercicio de la profesión no se entendía solo en términos de la satisfacción de una pasión individual (el amor a la ciencia), sino que tenían una clara dimensión colectiva. Desde, al menos, los años 1820 hasta el Sexenio Democrático inclusive estuvo muy presente en los textos de los médicos e ingenieros una retórica del amor dirigido hacia un objeto colectivo: la comunidad, la humanidad. Así, por ejemplo, en el Trienio constitucional, los médicos se autodefinen como «amantes de la Humanidad", mientras que el "amor al bien público" aparece reivindicado como característica principal del cuerpo de ingenieros de caminos en la Revista de Obras Públicas de $1872^{45}$. Sin embargo, para tratarse de un amor legítimo y loable no hacía falta que su objetivo fuera la nación o la humanidad. Podía ser el mismo grupo profesional; por ejemplo, de los ingenieros de caminos se esperaba un «acendrado amor al Cuerpo á que tanto deben, el profundo sentimiento de gratitud que tamaña honra les inspira, y el noble ejemplo de sus antecesores que en momentos de ruda prueba supieron mantenerse con gloria dignos de la confianza que habían merecido» ${ }^{46}$.

En general, profesar el amor y dejar que este guiara las acciones de uno no se percibía como poco masculino. Todo lo contrario, el amor se realzaba como fuerza potente que motivaba a un hombre para actuar por el bien de la colectividad amada, reafirmando su papel activo y cargado de responsabilidad, como el demiurgo que ordena y moldea su entorno por el bien y provecho de todos. Por mucho que el amor per se no se entendía como poco masculino, hubo una diferencia implícita con las

42. Décadas médico-quirúrgicas, tomo 7, no 4, 1822, pp. 171-172.

43. Resumen histórico del arma de ingenieros en general, y de su organización en España, por un antiguo Oficial del Cuerpo de Ingenieros del Ejército, que desempeña boy un alto cargo en otra carrera, Madrid: Imprenta Nacional, Madrid, 1846. Publicado en Memorial de Ingenieros, 1-9, 1846, pp. 1-161, más apéndices pp. 163-190 y pp. 191-224.

44. Décadas Médico-quirúrgicas, tomo 1, no 7, 1820, pp. 345-6.

45. "Parte oficial», Revista de Obras Públicas, 1, 1872, pp. 1-2.

46. "Parte oficial», Revista de Obras Públicas, 1, 1872, pp. 1-2. 
formas de amar significadas como femeninas. Mientras que la noción de entrega y de sacrificio por amor fue compartida por y para ambos sexos, el amor de las mujeres se representaba como enfocado hacia los seres concretos (reales o imaginarios) y sólo tendía a elevarse hacia objetos abstractos o colectivos debido a la mediación de un ser querido (joven que se lanza contra el invasor después de que este ofendiera a su padre, esposa que lucha por la patria una vez el marido cayera en batalla o fuera ejecutado por los tiranos $)^{47}$.

A diferencia de un amor íntimo y personal, reivindicar el amor hacia la colectividad era una forma de erigirse en representantes del bien común y de este modo inscribirse en la noción de hombre público, una de las expresiones máximas de la masculinidad romántica en la España de las décadas centrales del siglo XIX. Andrew Ginger argumenta que el ideal del hombre sensible fue particularmente potente en las culturas políticas del liberalismo avanzado y se mantuvo vigente en ellas más tiempo que en otras culturas políticas, y esta sugerente tesis nos lleva a plantearnos que eso podía explicar que los autores afines al progresismo y demorrepublicanos tenían tanta inclinación por los personajes idealizados de ingenieros, médicos y hombres de ciencia ${ }^{48}$. Desde el médico como «el ángel salvador que socorre a la humanidad» — como lo define Xavier Andreu - en las novelas de Ayguals de Izco, hasta los ingenieros y "científicos» martirizados por la superstición y la mala modernidad de Pérez Galdós analizados por Martykánová, los hombres que encarnaron la conexión entre las ciencias útiles, el amor y el bien común, constituían una "fantasía nacional» — retomando las categorías analíticas de Andreu- particularmente potente en el liberalismo avanzado ${ }^{49}$. El hecho de que médicos e ingenieros de carne y hueso abundaron también en las filas del progresismo ya requeriría una interpretación más cautelosa, porque los hubo también de otras afinidades políticas, y su protagonismo político tiene que ver más con el sentimiento compartido de deber y derecho de participar en la vida política que con una opción

47. MalečKová, Jitka: Úrodná půda. Žena ve službách národa, Praga: ISV, 2002. En este sentido resulta reveladora la construcción de la imagen de Mariana Pineda: SERrano, Carlos: "Mariana Pineda (18041831): mujer, sexo y heroísmo", en Burdiel, Isabel y Pérez Ledesma, Manuel (coords.), Liberales, agitadores y conspiradores: biografías heterodoxas del siglo XIX, Madrid: Espasa Calpe, 2000, pp. 99-126. Un ejemplo de cómo se resistían algunas mujeres de la época a estas interpretaciones de su implicación patriótica, véase la polémica entre Leona Vicario y Lucas Alamán en México de los 1830. Fuentes citadas en García López, Ana Belén: Las heroinas silenciadas de las independencias americanas, Barcelona: Megustaescribir, 2016, s.n.

48. Ginger, Andrew: “¿Un yo moderno para España? c. 1830-c. 1860». En Blanco, Alda y Thomson, Guy (eds.): Visiones del liberalismo. Política, identidad y cultura en la España del siglo XIX, Valencia: Publicacions de la Universitat de València, 2008, pp. 121-136.

49. ANDreu, Xavier: "Nación, emoción y fantasía. La España melodramática de Ayguals de Izco", Espacio, Tiempo y Forma, Serie V, Historia contemporánea, 29, 2017, pp. 65-92; MARTYKánová, Darina: «El amor condenado, el amor triunfante: El género en el discurso sobre la ciencia, la religión y la nación en tres obras de Benito Pérez Galdós», Espacio, tiempo y forma. Serie V, Historia contemporánea, 29, 2017, pp. 149-179. 
ideológica concreta. El interés activo por los asuntos públicos era uno de los rasgos principales de la masculinidad para los hombres de clases medias y altas: encontramos pautas parecidas ya entre las élites patrióticas ilustradas (v.g. sociedades de los amigos del país), pero es indudable que este elemento salió reforzado discursivamente de las revoluciones liberales y su significación masculina se acentuó cuando las mujeres fueron empujadas a los márgenes de la esfera pública después de la consolidación definitiva del liberalismo y de sus instituciones políticas ${ }^{50}$. Los ingenieros y los médicos se esforzaron por inscribirse en este ideal como hombres de ciencia, sin renegar al mismo tiempo de participar activamente en la política como individuos adictos a las distintas corrientes políticas del momento ${ }^{51}$.

Las referencias al grupo se aprecian también en el reconocimiento explícito de la búsqueda de la gloria y del aprecio de los pares como una motivación legítima de las acciones de un hombre. La masculinidad romántica no era ante todo individualista, sino que se trataba de un proyecto con dimensiones colectivas. El discurso profesional de los años 1820-1860, sobre todo en las primeras décadas del periodo, más que glorificar un individuo que buscara la verdad a pesar del oprobio o desinterés de los otros, ponía énfasis en la fuerza del reconocimiento social y de la emulación. Se entendía no sólo como obvio, sino como bueno que un hombre buscara el aprecio de sus pares, es decir, de otros hombres de su clase. El lenguaje de la época hablaba en términos de seguir el ejemplo, de excitar el celo, de la emulación. Los buenos médicos e ingenieros, como todos los buenos hombres, buscan la verdad usando la razón, pero también la gloria, que, en otros términos, significa el reconocimiento entre los que importan, es decir, los hombres de criterio, sus pares ${ }^{52}$. De esta forma, el médico y diputado Mateo Seoane (1791-1870) apelaba a las Cortes del Trienio para que se autorizara y se proporcionasen medios a los médicos voluntarios para llevar a cabo experimentos en lugares donde apareciera la fiebre amarilla:

¿no vemos ofrecerse ya un médico, conocido por su ilustración en toda la península, á hacer en sí mismo los experimentos necesarios? ¿y podremos dudar que le seguirán

50. Romeo, María Cruz: "Domesticidad y política. Las relaciones de género en la sociedad posrevolucionaria». En Romeo, María Cruz y Sierra, María (coord.): La España liberal, 1833-1874, Madrid: Marcial Pons, 2014, pp. 89-130; PEyrou, Florencia: «Mujeres en el espacio público de la España liberal, 18081874». En Martin Berbois, J. L. y TAVERA, S. (eds.): Sufragisme i sufragistes: reivindicant la ciutadania politica de les dones. Barcelona: Generalitat, 2019, pp. 21-55.

51. Como ejemplo presentamos tres instantáneas de la penetración de los profesionales médicos en las cámaras legisladoras. En las Cortes del Trienio Liberal hubo un total de diecisiete médicos (al menos de formación médica, no necesariamente ejercieron todos la profesión), en las Cortes de 1845 hubo once diputados titulares y un senador, por último en el congreso constituyente del Bienio Progresista resultaron electos doce representantes médicos. El Siglo Médico, 6-8-1854 y MARTYKÁNOVÁ, Darina y NúÑEZ-GARCía, Víctor M.: «Luces de España... op. cit.

52. El Siglo Médico, 30-7-1854. 
otros en tan gloriosa carrera? Por lo que toca á la exposición, cuya lectura ha motivado lo que acabo de exponer, sería hacer un agravio á la sabiduría de las Cortes el intentar tan siquiera alabarla; es tan laudable y tan superior á todo elogio la propuesta es tan digna de esta época fecunda en acciones gloriosas que yo me limito á pedir, que resolviendo las Cortes haberla oído con particular agrado se remita con recomendación al Gobierno, dando así el Congreso una muestra del aprecio con que admite las ofertas dignas de hombres libres, y excitando la emulación de los que ansíen buscar la gloria, premio el más digno de las almas generosas ${ }^{53}$.

La búsqueda de la gloria y el reconocimiento de los pares habían sido elementos importantes en la masculinidad de las élites ilustradas. Sin embargo, las revoluciones liberales redefinieron el contexto discursivo en el que se desplegaran estas prácticas establecidas. Se enfatizaba la libertad de los hombres en busca de gloria en un nuevo régimen de libertades (la España libre) y la nación soberana constituía la comunidad de referencia y el marco de acción básicos, que mediaba entre el hombre y la Humanidad, incluso en las hazañas científicas, por mucho que las ciencias se entendían como una empresa universal:

Nada por otra parte podrá ser más glorioso para los españoles que el tomar la iniciativa en los trabajos que exige la resolución de esta disputa importante y en los experimentos de los cuales debe salir la luz que ha de hacer ver cuál es en sí una de las cuestiones más dignas de la atención de les hombres; dejemos á los déspotas el que mirando el contagio como un medio útil en política, desdeñen el bien de la humanidad; dejemos á ese gobierno caduco, que quiere edificar en el siglo 19 un tono nuevo sobre cimientos góticos, que admita contagios sin fin para tomar en esta creencia ridículos pretextos y organizar ejércitos que bajo el título de cordones sanitarios ataquen esta libertad que á su despecho va propagándose con más actividad aún que la fiebre que tanto muestra temer; dejémosles y la libre España tome la iniciativa en este género de gloria como la ha tomado en tantos otros y libre á la especie humana, si es posible, de uno de los males más terribles que la agobian ${ }^{54}$.

Solo con desempeñar bien su profesión, estos hombres servían a España, ayudando situarla firmemente entre las llamadas "naciones cultas», en un proceso de emulación pacífica entre las naciones que repercutía favorablemente en el progreso de la civilización ${ }^{55}$ :

53. Décadas médico-quirúrgicas, tomo 7, $\mathrm{n}^{\circ}$ 1, 1822, pp. 29-35. [Discurso completo]

54. Décadas médico-quirúrgicas, tomo 7, n $\mathrm{n}^{\circ} 1,1822$, p. 32.

55. Retortillo, Ángel: "Caminos de hierro", Revista de obras públicas, 3, 1853, pp. 25-29. En el artículo, este ingeniero de caminos habla directamente sobre el "pertenecer a la gran familia europea». Como ejemplo de la visión de la comunidad de los países civilizados, extendida en los años cincuenta y sesenta: «QQuién es... tan ignorante que no conozca que los pueblos más adelantados que avanzan ancha y llanamente por el camino de la civilización no solo remueven los obstáculos, sino que prodigan toda clase de auxilios al 
La Medicina y cirugía han sido desde su origen el más constante apoyo de la salud y vida humana; y habiéndose mirado siempre entre las naciones más cultas como un objeto digno del mayor aprecio la ocupación de las plumas que se han dedicado a propagar las luces y conocimientos ${ }^{56}$.

Este juego complejo entre la universalidad de las ciencias, el bien de la Humanidad y la posición de España entre los países civilizados (o "la gran familia europea»), que desplegaron en su discurso profesional tanto los médicos, como los ingenieros, les permitía situarse en la posición de representantes del bien común tanto si ocuparon cargos administrativos, participaron en la política o ejercieron su profesión en el mercado. De este modo, pudieron reclamar beneficios, cargos y actuación gubernamental a su favor, y al mismo tiempo presentarse como benefactores desinteresados de la comunidad, y, de este modo, encarnar una de las figuras clave de la masculinidad romántica, la del hombre público.

\section{El VAlOR y EL HONOR DE LOS HOMBRES DE CIENCIA}

El valor y las características marciales son rasgos que han sido significados como masculinos con gran frecuencia y durabilidad a nivel mundial en muy diversos contextos sociales. Aun así, podemos constatar que en Europa y América del primer tercio del siglo XIX salieron reforzados como elementos fundamentales de la masculinidad romántica, ostentando en ella mayor peso que en la masculinidad ilustrada. Como han mostrado Lucy Riall y otros para la Europa revolucionaria en general (sin dejar de lado las repúblicas latinoamericanas) y Xavier Andreu para el caso español en particular, las guerras napoleónicas y las revoluciones liberales pusieron el foco en jóvenes patriotas dispuestos a alzarse en armas a favor de la soberanía nacional y una vez conseguida la victoria, entregar el poder a las autoridades políticas constitucionales ${ }^{57}$. Los hombres de ciencia como los médicos o los ingenieros hidráulicos, que habían logrado construir para sí una imagen de ciudadanos de la República de las Letras, caballeros sosegados

desarrollo de la riqueza pública, en la que fundan su grandeza y poderío? ¡Ay de nosotros si dejamos de imitarles! Pues bien, para igualarles, imitemos sus adelantos, y dejando á un lado rancias preocupaciones caminemos sin temor por la senda del progreso material, pues solamente así podremos alcanzar el lugar privilegiado que nos señale la Providencia entre los pueblos libres, ilustrados y venturosos». En GARRIGA Y RocA, Miguel: "Memoria que acompaña al plano de la ciudadela de Barcelona y proyecto de su derribo", Revista de Obras Públicas, 3, 1863, pp. 29-34.

56. Décadas Médico-Quirúrgicas, tomo 1, nº 1, 1820, p. 1.

57. Riall, Lucy: "Men at War: Masculinity and Military Ideals in the Risorgimento». En PatriarCa, Silvana y Riall, Lucy (eds.): The Risorgimento Revisited, Londres: Palgrave Macmillan, 2012, pp. 152-170; DuDINK, Stefan, Hagemann, Karen y Tosh, John (eds.): Masculinities in Politics and War. Gendering Modern History, Manchester/Nueva York: Manchester University Press, 2004. 
de tacto fino y con capacidad para agradar a sus superiores y manejar hábilmente a sus inferiores, tuvieron que renegociar su representación frente al poder simbólico de los oficiales, que se beneficiaba de esta popularidad reciente de la figura del patriota en armas a la vez que bebía de una tradición del honor militar consolidada desde el Antiguo Régimen.

Nuestra investigación confirma que, efectivamente, dos momentos revolucionarios importantes como el Trienio constitucional y la revolución de 1854 fueron para los hombres de ciencia momentos de una negociación febril con este ideal marcial de la masculinidad romántica. Es más, incluso en periodos cuando la convulsión bélica se mantenía localizada, como fue el caso de la primera guerra carlista, se observa cierta militarización del imaginario y de la práctica de las ciencias. Un ejemplo sería la introducción del uniforme para los cuerpos de ingenieros al servicio de la Administración civil (minas, caminos y montes), además de aparecer elementos de disciplina castrense en sus respectivos reglamentos, algo que destaca en comparación con las prácticas que caracterizaron estos grupos — todavía poco articulados- en las décadas 1790-1810.

En el Trienio, fueron sobre todo los médicos, un grupo profesional numeroso y bien representado en las nuevas instituciones, los que desplegaron armas discursivas para erigirse en hombres de valor, en términos de igualdad con los milicianos y oficiales del ejército. Esta negociación no fue solamente una cuestión de identidad y de prestigio social, sino que estaba expresamente ligada a la jerarquía de mando y a la reivindicación de cargos y honores públicos.

No obstante por una irreflexión muy extraña entre personas de algún discernimiento, un ayudante militar se cree con superioridad para mandar sobre un médico. ¿En qué se funda este error tan craso, como envejecido? En que la milicia responde, es la clase predilecta del Estado; pues, expone su vida en su defensa. Está bien: pero sin ir más adelante, pregunto ¿¿quién la expone mas ¿el militar, o el médico?

Aquel solo en los ataques, que duran poco: éste en todas las enfermedades, que son de todos los tiempos. Aquel solo en determinadas épocas y precisas horas; éste en todos los momentos de su vida, de día, y de noche. Aquel solo con los enemigos de la patria, y por consiguiente suyos: este tanto con sus enemigos, como con sus amigos; pues para él son hermanos todos los hombres. Aquel tiene medios indefinidos de ofensa, y defensa: éste arrostra indefenso y generoso el evidente peligro propio, para aliviar el ajeno. Baste para confirmación decir que el militar más valiente y aguerrido tiembla al declararse una epidemia, y se estremece a la sola voz de contagio. En ese campo de batalla natural brilla exclusivamente la heroica serenidad del médico acompañado solo de sus luces y filantropía ${ }^{58}$.

58. Décadas médico-quirúrgicas, tomo 1, n 2, 1822, pp. 66-75. [Exposición hecha al congreso por el diputado médico José Francisco Pedralbes]. 
Por mucha convicción de que la serenidad y el temple frente a la enfermedad constituían una forma válida de mostrar coraje que se aprecia en este discurso, la atracción que ejercía la figura del hombre guerrero como la encarnación máxima del valor es evidente. Las referencias frecuentes a los militares en el discurso de los médicos denotan el prestigio del hombre en armas en un contexto de revolución y guerra, y el esfuerzo de los médicos por lograr el reconocimiento como iguales pasaba no solo por compararse con los militares, sino también por asemejarse a ellos en la reivindicación del valor y de la utilidad para la causa revolucionaria.

Pertenezco a la medicina militar, y ciertamente que es el título que más aprecio, porque me recuerda memorias que llenan de satisfacción mi corazón. He visto un ejército de la Nación en circunstancias sumamente apuradas; ejército que hubiera perecido víctima de un contagio si sus médicos, entre los cuales tengo la honra de contarme, no hubiesen tenido el noble arrojo de denunciar a la autoridad la existencia del contagio y sus terribles consecuencias; y si no hubieran sostenido con carácter inflexible una verdad tan útil como arriesgada en medio de una oposición abierta de parte del vulgo, y lo que es más, de algunas autoridades que podían hacerles mucho daño. Tengo la dulce satisfacción de haber contribuido en gran parte a tan benéfica empresa; satisfacción que nadie arrancará de mi pecho59.

Sin embargo, a mediados del siglo XIX, el panorama era mucho más complejo y matizado. Cuando El Siglo Médico ensalzó la actuación de los médicos de Madrid durante los combates en la revolución de julio de 1854, no lo hizo asemejando su valor al de los combatientes, ni siquiera afirmando que el valor de los médicos era superior al de los que empuñaron las armas. Todo lo contrario, la revista opuso la entrega valerosa y desinteresada de los médicos al caos y alboroto causado por los que alteran el orden, movidos por el odio y la venganza. Tampoco es casualidad que este periódico médico más bien conservador hablara de la medicina en términos de religión y sacerdocio, de la misma forma que intentaban inculcar a los aspirantes a ingeniero los fundadores de la Escuela de montes:

Allí donde reinaban el odio y la venganza con todo su terrorífico aparato, se presenta el hombre sereno y tranquilo, lleno de caridad, de amor y de ciencia, exponiéndose inerme a los estragos del plomo mortífero para arrebatarle sus víctimas, para llevar consuelo a los vencidos y aplacar el rigor de los vencedores. Este hombre es el médico-cirujano, quien deteniendo las pérdidas de sangre irreparables, cerrando las heridas abiertas, reponiendo partes dislocadas, separando otras cuya conservación es peligrosa, extrayendo cuerpos extraños y remediando, en fin, todas las lesiones que de ello son susceptibles, consigue salvar a la gran mayoría de los heridos y reducir de este modo a pequeñas proporciones los funestos efectos de la calamidad a la que aludimos. [...] Madrid, atribulado por los sangrientos que acaba de presenciar, han presentado los profesores la más humanitaria,

59. Diario de Sesiones de Cortes, 1-1-1823, p. 1208. [Discurso del diputado Mariano Lagasca] 
la más benéfica de las ciencias [...] Y todo esto sin esperanza de ascensos, ni de mejorar sus fortunas, ni por ningún tipo de interés personal o de clase. ¡Ah! Que la medicina es la segunda religión de la humanidad y que la ejercen sus sacerdotes consagrados a la práctica de la más sublime virtud de la religión verdadera ${ }^{60}$.

Una vez consolidado el régimen liberal, ganó prominencia el discurso de armonía entre naciones hermanadas, configurado ya en la Francia revolucionaria con elementos del discurso ilustrado sobre los beneficios del comercio y la libre circulación, que mantenía que las guerras eran una cosa del pasado y que el progreso de la civilización consistía en una competencia benévola entre las naciones cultas. Esta competencia se llevaría a cabo mediante el comercio, facilitando los gobiernos la circulación de bienes y personas, y mediante los adelantos de las luces, tanto en términos de esforzarse cada nación en contribuir a los progresos en el conocimiento científico, como a la hora de poner los adelantos al alcance del pueblo. Además, esta competencia no siempre era tan benévola como se presentaba; desde los años 1820 se fue acentuando en un nuevo contexto euro-americano de la construcción nacional la pugna por establecer una jerarquía de prestigio entre las naciones "civilizadas», dentro de la categoría de "Europa» u "Occidente». Los españoles con cierto mundo eran conscientes de que el discurso transnacional de la civilización tendía a marginar España al menos desde la época ilustrada, acentuándose esta dinámica desde la caída del Trienio constitucional y adquiriendo pautas orientalizantes. ${ }^{61}$ Los médicos y los ingenieros se insertaron muy hábilmente en este discurso, apuntando que su contribución —-bien recompensada en términos de dinero y de cargos y honores públicos- era decisiva para que España se situase y mantuviese entre las naciones adelantadas que marchaban a la cabeza de la civilización europea:

Las sociedades modernas, que han abandonado las huellas de sus predecesoras, para quienes la invasión y el pillaje fueron, en unas, los medios de conquista y adquisición, y la servidumbre, en otras, el fundamento de la conservación y pacífica posesión de aquellas sangrientas conquistas, y que han reconocido al trabajo libre como base de su existencia, no han podido menos de considerar á las vías de comunicación, como sus más poderosas auxiliares para el desarrollo de la prosperidad y riqueza públicas [...] No son necesarias más explicaciones para comprender que el objeto de las vías de

60. El Siglo Médico, 30-7-1854. Para ingenieros de montes: Casals Costa, Vicente: Los ingenieros de montes en la España contemporánea, 1848-1936, Barcelona: Ediciones del Serbal, Barcelona, 1996, pp. 38-40. Juan Pan-Montojo ha puesto la palabra apostolado directamente en el título de su libro sobre los ingenieros agrónomos: Pan-Montojo, Juan: Apostolado, profesión y tecnología. Una bistoria de los ingenieros agrónomos en España, Madrid: Asociación Nacional de Ingenieros Agrónomos, 2005.

61. ANDREu Miralles, Xavier: «El triunfo de Al-Andalus: Las fronteras de Europa y la '(semi)orientalización' de España en el siglo XIX," Saitabi, 55, 2005, pp. 196-198; Simal, Juan Luis y MARTYKáNOVÁ, Darina: "Ferdinand and the Sultan"... op. cit. 
comunicación en nuestra época, es trasportar las personas y las cosas en las condiciones más ventajosas de comodidad, celeridad y economía; objeto, cuya más noble consecuencia es la preponderancia social de la inteligencia sobre el injusto poder de la fuerza material del hombre ${ }^{62}$.

Generalizar de una manera ordenada la asistencia médica, con el doble objetivo de conseguir que todas las clases de la sociedad, en todos los pueblos y a todas horas hallen los auxilios necesarios, y que los profesores del arte de curar, sobre la decorosa retribución que corresponde a su larga y dispendiosa carrera literaria y científica, alcancen la consideración debida y la precisa estabilidad, son las necesidades que el gobierno, bien aconsejado en este punto, ha querido satisfacer. Satisfaciendo estas necesidades se ha adelantado el gobierno español a los de las naciones más cultas de Europa, y ha reivindicado así para nuestra patria una mínima parte de la gloria que en tiempos más prósperos le cupo de marchar a la cabeza de la civilización europea ${ }^{63}$.

Tanto los médicos, como los ingenieros se construyeron como sujetos que civilizan el mundo que les rodea mediante su actividad profesional, actuando sobre la naturaleza - sobre todo los ingenieros - y sobre la vida — sobre todo los médicos - algo que en otros contextos sería monopolio divino. Esa capacidad para actuar sobre el mundo y poseerlo a través del conocimiento y de civilizarlo a través de su intervención se concebía como un monopolio masculino y formaba parte clave en la construcción del hombre liberal y moderno, a la vez patriota y parte de las élites mundiales que se reconocían mutuamente como hombres destinados a liderar sus respectivas comunidades de referencia (naciones, pero también imperios o grupos etnorreligiosos) por su educación moral y científica y, sobre todo, capacidad a la hora de hacer uso de la razón.

Este discurso culminó en los años 1860 cuando, por ejemplo, los ingenieros aspiraron con gran autoconfianza a erigirse en la «aristocracia de nuestro siglo; aristocracia que ha de buscar sus blasones en el estudio y la ciencia; sus hazañas en el trabajo; sus títulos solo en el nombre de quien sepa hacer de su nombre su verdadero título de grandeza " ${ }^{64}$. No obstante, al mismo tiempo existieron grandes tensiones y puntos contradictorios. Tanto los médicos como los ingenieros hicieron uso de prácticas y signos de prestigio asociados con el hombre de élite del Antiguo Régimen (proximidad a la Corte) y continuaron usando el lenguaje militarizado (jinetes incansables, hazañas, batallas, heridas, puestos de combate) heredado de las décadas 1820 y 1830 hasta el final del Sexenio Democrático, aunque fuera con un mayor énfasis en los elementos colectivos frente a una visión más individual de la heroicidad, particular de la masculinidad romántica ${ }^{65}$.

62. Retortillo, Ángel: «Caminos de hierro», Revista de obras públicas, 3, 1853, pp. 25-29.

63. El Siglo Médico, 30-7-1854.

64. Revista de Obras Públicas, 2, 1863, p. 27.

65. Todas estas expresiones en «Parte oficial», Revista de Obras Públicas, 2, 1872, pp. 13-14. 
Si el valor, aun definido de formas distintas, ha sido reconocido en la historiografía como parte clave de las masculinidades de la época, no lo ha sido tanto la movilidad. Es cierto que algunos lugares comunes en la historiografía enfocada a las clases trabajadoras apuntan a una asociación implícita entre la masculinidad y la movilidad, sobre todo la movilidad independiente ${ }^{66}$. Raúl Mínguez explora la negociación compleja que hicieron las religiosas de clases acomodadas para justificar su movilidad independiente por el territorio español en el marco de sus nuevas iniciativas de organización y de beneficencia ${ }^{67}$. Planteamos la hipótesis que en España la movilidad independiente fue un elemento importante de la masculinidad de las élites decimonónicas y jugó un papel clave a la hora de señalar como masculinas las distintas carreras de ingeniero y también, aunque en menor medida, la profesión médica. A diferencia, por ejemplo, de la construcción de las relaciones de género en Inglaterra (donde, por otra parte, las mujeres sufrieron más trabas a la hora de heredar y gestionar la propiedad que en España y la sociabilidad de las élites tendía a ser más segregada), en España la movilidad independiente ( de clases acomodadas fue particularmente difícil de negociar, aun si fueran acompañadas por personas de clases «inferiores», en calidad de servicio ${ }^{68}$. En nuestra opinión, no debemos perder eso de vista a la hora de interpretar la narrativa heroica de los hombres que hicieron de las ciencias su sustento. La movilidad parece jugar un papel más decisivo que la fuerza física, problemática en la época desde el punto de vista de clase. Los ingenieros de caminos ponían énfasis en cómo sus tareas en su primer destino consistían en largos viajes a caballo para supervisar el estado de las carreteras y el trabajo de los peones camineros (entre ellos mujeres, por cierto). Los ingenieros de minas se presentaron como héroes de la civilización en el territorio hostil, solos frente a los obreros «embrutecidos» en los lugares remotos donde se encontraban los recintos mineros. Los fundadores de la Escuela de Montes alegaron haber introducido largas caminatas entre las actividades obligatorias para que un joven ingeniero impusiera respeto con su fortaleza y aguante a los guardias forestales cuando se desplazara con ellos a inspeccionar los bosques ${ }^{69}$. Los médicos rurales subrayaron lo penoso y

66. Por ejemplo asociando la migración transfronteriza con los varones por mucho que las mujeres representaran un porcentaje importante de los migrantes.

67. Mínguez Blasco, Raúl: Evas, Marías y Magdalenas: género y modernidad católica en la España liberal (1833-1874), Madrid: Centro de estudios políticos y constitucionales, 2016.

68. Sobre las viajeras británicas: Baumgarten, Murray y Franchi, Barbara: «Modernity and Mobility: Victorian Women Travelling. Introduction to the Forum," Partial Answers: Journal of Literature and the History of Ideas, 16 (1, 2018), pp. 89-93; RoBinson, Jane: Unsuitable For Ladies: An Anthology of Women Travelers. Nueva York: Oxford University Press, 1994.

69. TORRE, Bernardo de la: «Testamento forestal de Bernardo de la Torre Rojas, fundador y primer director de la Escuela de ingenieros de montes (1866)». En BAUER MANDERSCHEID, E., Los montes de España en la historia, Madrid: Servicio de publicaciones agrarias/Fundación Conde del Valle de Salazar, 1991, pp. 519-528. 
heroico de su destino, haciendo énfasis en los desplazamientos diurnos y nocturnos para salvar las vidas de los pacientes ${ }^{70}$. Incluso la práctica más típica para la mayoría de los médicos de la época, la de visitar a los pacientes en sus casas, podría resultar comprometedora para una mujer. Es decir, lo que para un hombre resultaba sin importancia o hasta era signo de su valor y entrega, en una mujer significaría poner en duda su honra y exponerse a la pérdida de reputación. Así, este rasgo quedaba construido como masculino en su relación con el espacio y con el movimiento, reforzando la noción de hombres como sujetos que mediante sus acciones civilizan el mundo, por que se fue constituyendo en la época.

Honor era un concepto muy presente no solo en la construcción de las masculinidades en la España decimonónica, sino también en las autorrepresentaciones profesionales y los discursos sobre la práctica científica, algo que se aprecia a nivel europeo ya en la Edad Moderna ${ }^{71}$. No se trataba en absoluto de una particularidad española, latina o mediterránea: las referencias al honor eran constantes en el discurso de los médicos franceses a mediados del siglo XIX y en Alemania finisecular llegaron a proliferar los tribunales de honor (ärtzliche Ehrengerichte) donde los médicos dirimían sus conflictos profesionales ${ }^{72}$. La medicina se había establecido como una profesión honorable, digna de un caballero, desde el Antiguo Régimen, y los cirujanos habían ido ganando respetabilidad hasta lograr la equiparación plena con los llamados "profesores de medicina». Sin embargo, el concepto sufrió algunas transformaciones importantes en el siglo XIX y los médicos e ingenieros se construyeron como hombres de honor de formas variadas. En general, todos plantearon su actividad facultativa en términos de servicio desinteresado al bien común. El desinterés estaba estrechamente ligado a la noción de la autonomía, una característica principal del hombre plenamente «libre». No obstante, los ingenieros y los médicos se construyeron como «desinteresados» movilizando elementos distintos. Reconocían como motivación legítima para el ejercicio de su ciencia la búsqueda de gloria y reconocimiento de los pares. La fuente principal del desinterés era, sin embargo, el amor: el «amor a la verdad» (ingenieros y médicos, en

70. Carlos Lucía en uno de sus artículos defendió la reforma de partidos médicos de 1854, reforma que afectaba fundamentalmente a los médicos rurales y que en teoría mejoraba sus condiciones económicas, para ello justificó las penosas condiciones de vida de estos médicos entre otras cuestiones por «recorrer distancias inmensas [...] sin el necesario promedio de tiempo, a no ser empleando medios estrepitosos, que si son aplicables, ni fueran en caso alguno adoptados por la sensata profesión de curar». El Siglo Médico, 2-4-1854.

71. Biagoli, Mario: Galileo, Courtier: The Practice of Science in the Culture of Absolutism, Chicago: The University of Chicago Press, 1993; SHAPIN, Steven: A Social History of Truth: Civility and Science in Seventeenth-Century England, Chicago: The University of Chicago Press, 1994.

72. NyE, Robert: "Medicine and Science as Masculine "Fields of Honor"», Osiris, 12 (2 serie), 1997, pp. 60-79; NyE, Robert: "Honor Codes and Medical Ethics in Modern France», Bulletin of the History of Medicine, 69, 1995, pp. 91-111; Maenle, Andreas-Holger: "Doctors in Court, Honour, and Professional Ethics: Two Scandals in Imperial Germany», Gesnerus, 68-1, 2011, pp. 61-79. 
tanto que hombres de ciencia), el "amor a la Humanidad» (médicos), el "amor al bien público»33 (ingenieros del Estado). Hay una paradoja interesante entre esta retórica del desinterés y el hecho de que, mientras el dominio de la ciencia no fuese a priori construido como masculino, la práctica remunerada de la ciencia sí que lo era.

El honor derivado de la libertad, de la independencia y del servicio desinteresado a la comunidad entraba en una negociación compleja con la propiedad y las formas de ganarse el sustento. En la primera mitad del XIX, los médicos eran en su mayoría profesionales recompensados por sus servicios mediante honorarios. Este arreglo les dotaba a priori de consideración como hombres libres en términos de no ser empleados de otro hombre. La relación entre el médico y el paciente encajaba con facilidad en la lógica liberal, siempre teniendo en cuenta que los médicos de la época exigieron al Estado que garantizara que personas sin credenciales adecuadas quedasen excluidas de la profesión. Sin embargo, la cuantía de los honorarios resultaba fundamental en un marco político en el que la ciudadanía plena dependía de criterios materiales (derecho censitario de voto), por mucho que los médicos, igual que los ingenieros estaban exentos de este requerimiento al entrar en la categoría de las capacidades. ${ }^{74}$ Por lo tanto, lejos de entenderse el servicio desinteresado como incompatible con la búsqueda del beneficio material, los médicos constantemente reivindicaron buenos honorarios para todas las clases médicas, ya que la situación material de un médico repercutía en el honor de toda la profesión:

¿Qué son los honorarios del médico? El fruto de su trabajo con inteligencia, como capacidad que necesita la sociedad en momentos dados, lo mismo que a todas las otras, sin que nuestra jerarquía, descuidad en extremo y apenas en embrión, nos obligan a la ridícula y extravagante manía de algunos que nos solicitan como a sacerdotes y nos desprecian y mandan como a menestrales. [...]

Somos profesores que ejercen una industria, y de ella, como todos, queremos recompensa en el mercado general. Pero ¡qué anárquico, que abandono se halla nuestro cuerpo económico! [...] Todos piden recompensa según sus servicios y tiempo perdido, siga el médico en esto las huellas de los demás; que aún así no será fácil le aventaje nadie en sacrificios por el bien de la Humanidad ${ }^{75}$.

El discurso profesional de los médicos mostraba una preocupación constante por la situación de los médicos al servicio de los ayuntamientos, cuya baja remuneración y la dependencia de los «caprichos» de los concejos amenazaba su estatus como hombres de honor:

73. El «amor al bien público» aparece reivindicado como característica principal del cuerpo de ingenieros de caminos en "Parte oficial»: Revista de Obras Públicas, 1, 1872, pp. 1-2.

74. Jover, José María: «Situación social y poder político en España de Isabel II» en Jover, J. M.: Política, diplomacia y humanismo popular, Madrid: Turner, Madrid, 1976.

75. El Siglo Médico, 15-1-1854. 
Si miramos á los de los pueblos, los veremos casi á todos dependientes de la ignorancia y arbitrariedad de los concejos, y en medio de la esclavitud y la indigencia; y si atendemos á los de la corte y demas ciudades populosas, advertiremos, que exceptuando los de la real casa, y algunos otros pocos que por su opinion ó fortuna se han proporcionado la subsistencia; la de los demás se puede decir que pende de la gratitud y voluntad de los enfermos: y así es, que hay muchos en el día, que sin ser pobres, pagan tarde, mal ó nunca las visitas y curación de sus males, y sin embargo es muy raro el profesor que los demanda ante la justicia para obligarlos á que les den su honorario. Estas verdades las anunciamos solo para hacer ver que á pesar de la poca consideración y honor, y el ningún premio que se les ha dispensado y dispensa á los médicos en España, son tal vez los que ejercen en la Europa su profesión con más desinterés, celo, humanidad y decoro ${ }^{76}$.

Los médicos no dudaron en movilizar la retórica patriótica, vinculando el honor de la patria y su lugar en el mundo al reconocimiento material y simbólico de la profesión médica, una operación que les ayudaba solventar la tensión entre el presentarse como básicamente desinteresados y al mismo tiempo reclamar alta remuneración, cargos públicos y honores.

Los ingenieros españoles de la época estaban en una situación algo distinta, debido al peso de los cuerpos del Estado. Para empezar, los que aspiraban a estudiar en las escuelas de ingenieros, militares y civiles, tenían que demostrar que el honor les venía de la cuna, que su familia fuera "honrada sin difamación". ${ }^{77}$ Asimismo se presuponía la existencia de un honor colectivo de los cuerpos, inculcado en las escuelas y salvaguardado por los mecanismos de selección, promoción y vigilancia. En este sentido se observa una clara apropiación sobre todo a partir de los 1830 de las nociones del honor militar, si bien es cierto que desaparecieron definitivamente elementos como la nobleza o la limpieza de sangre. Escudados en su conocimiento, mérito, trabajo, utilidad y mecanismos institucionales que les protegían de todo tipo de presiones, los ingenieros del Estado, igual que los médicos que ocuparon cargos en la Administración pública, como los médicos-directores de baños, se presentaron sistemáticamente como representantes del bien común, aunque tal pretensión se vio cuestionada desde las posiciones liberales y demorepublicanas, al percibirse su monopolio en ciertos ámbitos como privilegio ilegítimo, comparable a los gremios del Antiguo Régimen ${ }^{78}$.

76. Décadas Médico-Quirúrgicas, tomo 2, nº 2, 1820, pp. 63-64.

77. Reglamento para la Academia especial del Arma de Ingenieros, Madrid: Imprenta del Memorial de Ingenieros, 1859.

78. Martykánova, Darina: «Remover los obstáculos: los ingenieros de caminos españoles y sus visiones del Estado durante la segunda mitad del siglo XIX", Historia y Política. Ideas, procesos y movimientos sociales, 36, 2016, pp. 49-73; Ruız, Violeta: «[U]n recurso moral para vencer la enfermedad que he padecido: Neurasthenia, honour and composure in Justo María Zavala's memoirs (1899)», Cultural History (en prensa). 


\section{Conclusiones}

Los médicos e ingenieros construyeron su autorrepresentación con elementos heredados del Antiguo Régimen cuando, como explica Maria Malatesta, «el ideal tipo de profesional-caballero era un individuo educado que frecuentaba la buena sociedad y era capaz de mantener el justo equilibrio entre el honor y la utilidad ${ }^{79}$. Sin embargo, en las décadas de los 1820-1860 tuvo lugar una renegociación importante de este ideal, integrando pautas de la masculinidad romántica. Esta construcción de género era un proyecto explícitamente colectivo, basado en la búsqueda de la gloria y del reconocimiento de los pares y ligado a la gloria de la nación. La emulación era la dinámica clave: los hombres debían emular a los que habían logrado distinguirse por sus méritos superando todo tipo de obstáculos, y, como premio por este esfuerzo serían emulados por otros. En cierto contraste con el periodo de la Ilustración tardía, en la época de las revoluciones liberales el discurso profesional de estos hombres de ciencia resaltaba la heroicidad y el sacrificio de los facultativos y sus prácticas fueron conceptualizadas en términos bélicos y militares. El discurso profesional tenía una alta carga sentimental; los ingenieros y sobre todo los médicos se construyeron como hombre amantes y sufridores, en tal que facultativos ejerciendo su ciencia. Queda evidente que el divorcio entre masculinidad y pasión/amor/emoción no es una constante en la historia contemporánea de la Europa occidental; es más, la pasión y los sentimientos no se percibían en contradicción con la razón y eran parte clave de la autorrepresentación de los hombres de ciencia españoles —y de otros países de Europa- como hombres y como profesionales científicos. En la España de la era de las revoluciones constitucionales, la contribución activa a la vida pública aparece como otro elemento clave de las masculinidades de las élites: también los hombres de ciencia aspiraron a insertarse en la noción del hombre público, útil para la patria y activamente contribuyendo al bien común. En el contexto transnacional de la reconfiguración de las categorías identitarias como Europa y el Occidente y la pugna discursiva por establecer una jerarquía de prestigio de las naciones dentro de estas categorías, los facultativos apelaron hábilmente no solo a la utilidad de sus conocimientos y de su trabajo para el bien común entendido en referencia implícita o explícita a la nación, sino también retomaron la práctica establecida — como demuestra Jorge Cañizares-Esguerra desde hacía siglos- de vincular el desarrollo de sus disciplinas con el honor de la patria y su posición entre las naciones civilizadas.

La masculinidad romántica en la que se insertaron los profesionales de la ciencia en el periodo analizado tenía una clara dimensión de clase. El discernimiento, la circunspección y el tacto fino, incluso la dulzura, se reconocían igual de importantes en el buen ejercicio profesional que las habilidades y conocimientos científicos, aunque

79. Malatesta, Maria: Professionisti e gentiluomini...op. cit. 
observamos que con la institucionalización de la ingeniería en los cuerpos del Estado, las características de este tipo pierden peso frente a pautas colectivas como el espíritu del cuerpo. Planteamos la hipótesis de que, hasta que se democratizara la masculinidad normativa hacia el ideal de una masculinidad nacional compartida a través de las clases sociales, estos hombres de élite no sentían tanta presión para diferenciarse de lo femenino. La construcción de la virilidad en su justa medida, de aquellos que se reconocían mutuamente como caballeros, se oponía ante todo a la hipermasculinidad bruta de los hombres subalternos, mientras que se producía una pugna sutil articulada en términos de hipomasculinidad, o masculinidad insuficiente, para determinar qué hombres eran dignos de encarnar el ideal. En el caso de las carreras del Estado y de las profesiones científicas, la exclusión de las mujeres mediante mecanismos institucionales y prácticas sociales de respetabilidad no estaba puesta en duda en los años 1820-60 de forma que generase gran preocupación y los esfuerzos se centraron sobre todo en reafirmar estas carreras y profesiones como dignas de un caballero.

Toda cronología es provisional e imperfecta. Hemos podido observar claramente las continuidades y rupturas con el ideal de la masculinidad ilustrada, y también es borrosa la frontera entre la masculinidad romántica y la masculinidad "positivista" de finales del siglo XIX. Algunas transformaciones, como el ocaso de la figura caballeresca frente a un mayor énfasis a elementos colectivos de la acción facultativa, la estandarización, la objetividad o el pretendido desapasionamiento, aparecen ya en la década de 1850, sobre todo entre los ingenieros. Otros rasgos, como el lenguaje del amor y del sacrificio, y la militarización del imaginario y de la práctica, tienen su apogeo en el Sexenio Democrático y los protagonistas de este periodo revolucionario los mantienen vivos en las décadas posteriores de la Restauración borbónica. 